\title{
A EDUCAÇÃO EM SAÚDE COMO ESTRATÉGIA PARA O CUIDADO À GESTANTE, PUÉRPERA E AO RECÉM-NASCIDO ${ }^{1}$
}

\author{
Regiane Veloso Santos², Cláudia Maria de Mattos Penna ${ }^{3}$
}

\footnotetext{
${ }^{1}$ Recorte da dissertação - Integralidade do cuidado à gestante, puérpera e recém-nascido: o olhar de usuárias. Programa de Pós-Graduação da Escola de Enfermagem da Universidade Federal de Minas Gerais (UFMG), 2009.

${ }^{2}$ Mestre em Saúde e Enfermagem. Enfermeira de Saúde da Família da Secretaria Municipal de Saúde de Belo Horizonte. Minas Gerais, Brasil. E-mail: regivel@bol.com.br

${ }^{3}$ Doutora em Filosofia da Enfermagem. Professor Adjunto do Programa de Pós-Graduação em Enfermagem da UFMG. Orientadora da dissertação. Minas Gerais, Brasil. E-mail: cmpenna@enf.ufmg.br
}

RESUMO: Trata-se de um estudo qualitativo, desenvolvido em uma Unidade Básica de Saúde, do município de Belo Horizonte. Teve como objetivo, compreender a percepção das usuárias sobre a Linha do Cuidado à Gestante, à Puérpera e ao Recém-Nascido. Os sujeitos da pesquisa foram 12 usuárias assistidas nesse serviço e a coleta de dados foi realizada por meio de entrevistas. Para a análise dos dados, foi utilizada a técnica de análise de conteúdo. Desse processo, emergiram quatro categorias temáticas. Uma dessas categorias originou este artigo e trata da educação em saúde como forma de cuidar. Representa um dos principais elementos para a promoção da saúde que contribui para a emancipação dos sujeitos e um espaço para troca de experiências e saberes, como demonstrado pelas mulheres que participaram deste estudo. Isso remete ao duplo papel exercido pelos profissionais de saúde que são também educadores por excelência.

DESCRITORES: Educação em saúde. Cuidado centrado no paciente. Saúde materno-infantil. Promoção da saúde. Enfermagem familiar.

\section{HEALTH EDUCATION AS A STRATEGY FOR CARE FOR PREGNANT WOMEN, PUERPERA, AND NEWBORN CHILDREN}

\begin{abstract}
This is a qualitative study developed and carried out in a Basic Health Care Unit located in Belo Horizonte, Brazil. It aimed to better understand female users' perceptions about the Line of Care offered to Pregnant Women, puerpera, and Newborn Children. The subjects were 12 women users cared for in this service and data were collected through interviews. Data were analyzed using the content analysis technique. From this process, four thematic categories emerged. One of these categories gave origin to this article and deals with heath care education as a form of care. It represents one of the principle elements of promoting Health Care which contributes to people's emancipation and a place to exchange experiences and knowledge, as shown by the women who participated in this study. This leads to a double role to be exercised from health care professionals, who are also educators by excellence.
\end{abstract}

DESCRIPTORS: Health education. Patient-centered care. Maternal and child health. Health promotion. Family nursing.

\section{EDUCACIÓN PARA LA SALUD COMO ESTRATEGIA PARA EL CUIDADO A LA MUJER EMBARAZADA, LA PUÉRPERA Y AL RECIÉN NACIDO}

RESUMEN: Es un estudio cualitativo realizado en una Unidad Básica de Salud del municipio de Belo Horizonte. Su objetivo fue comprender la percepción que las usuarias de este servicio tienen acerca de la línea Cuidado a la Mujer Embarazada, la Puérpera y al Recién Nacido. Los sujetos de la investigación fueron 12 usuarias atendidas en este servicio. La recolección de los datos se hizo mediante entrevistas. Para el análisis de los datos se utilizó la técnica de análisis del contenido. De tal procedimiento surgieron cuatro categorías temáticas, una de las cuales originó este artículo y trata sobre la educación para la salud como una forma de cuidado. Ella representa el elemento más importante para promover la salud y contribuye a la emancipación de los individuos, además de ser un espacio para el intercambio experiencias y de conocimiento, tal como fue dicho por las mujeres que participaron del estudio. Ello permite pensar en la doble función que desempeñan los profesionales de la salud que también son educadores por excelencia.

DESCRIPTORES: Educación en salud. Atencion dirigida al paciente. Salud materno-infantil. Promoión de la salud. Enfermería de la familia. 


\section{INTRODUÇÃO}

Na década de 1990, teve início a implementação do Programa Saúde da Família (PSF), atualmente denominado Estratégia de Saúde da Família (ESF), para contribuir para a construção e a consolidação do Sistema Único de Saúde (SUS), propondo a reorientação do modelo assistencial a partir da atenção básica. ${ }^{1-2}$ Desse modo, o PSF está pautado no trabalho em equipe multiprofissional e interdisciplinar, na adscrição da clientela em território definido, no estabelecimento de vínculo e na responsabilização sobre a população que reside em determinada área de abrangência. ${ }^{1}$

Desde 1998, a Prefeitura Municipal de Belo Horizonte-MG vem discutindo o redirecionamento das ações de saúde pautadas na integralidade da assistência, a partir do trabalho em equipe. Esse processo culminou com a implantação do PSF, em 2002, no programa BH-VIDA, ${ }^{3}$ e a seguir, com a proposta intitulada BH-VIDA: Saúde Integral. Esse projeto assistencial visa a construção de um sistema de saúde integral que viabilize a concretização da integralidade na prática cotidiana dos serviços de saúde. Além disso, pressupõe o trabalho centrado no usuário e operacionalizado por meio da construção de linhas do cuidado objetivando potencializar o trabalho em equipe, a fim de contemplar as necessidades dos usuários assistidos nos diversos serviços de saúde. ${ }^{4}$

No BH-VIDA: Saúde Integral, a produção do cuidado é organizada de forma sistêmica e de modo que os níveis de assistência estejam articulados. As linhas do cuidado integram os recursos disponíveis em fluxos de assistência que garantem ao usuário o acesso àqueles necessários a sua assistência. Além de se ter uma visão ampliada das linhas do cuidado, que articula todos os níveis de assistência, torna-se necessário compreendê-la enquanto ferramenta fundamental no processo de trabalho das equipes de saúde da família. "É importante reconhecer que há uma linha do cuidado operando internamente na Unidade Básica de Saúde, e que ganha relevância se consideramos que a maior parte dos problemas de saúde podem ser resolvidos neste nível da assistência". 5:132

Dessa forma, os profissionais da Unidade Básica de Saúde (UBS) São Gabriel, pertencente ao Distrito Sanitário Nordeste (DISANE) do município de Belo Horizonte, com o incentivo e a participação ativa da gerência local, decidiram colocar em prática a proposta de trabalho referenciada nas linhas do cuidado com a construção, entre outras, da Linha do Cuidado à Gestante, Puérpera e ao
Recém-Nascido, que foi implementada a partir do mês de março de 2005.

Essa proposta de trabalho surgiu a partir de problemas relacionados à integração das ações dos diversos profissionais envolvidos nesse cuidado e que levavam a resultados insatisfatórios tais como: pré-natal, puerpério e puericultura com acompanhamento desarticulado e descontínuo, baixo índice de aleitamento materno, dados de mortalidade neonatal e infantil por causas evitáveis, além da frustração declarada dos profissionais de saúde com os dados epidemiológicos.

Essa linha do cuidado, foi construída e implementada para garantir o cuidado necessário à gestante, puérpera e ao recém-nascido pela integração das ações dos profissionais envolvidos. Mesmo sendo construída para melhorar a assistência aos usuários, eles não participaram do planejamento da mesma em nenhum momento.

Alguns autores que discutem o processo de participação popular abordam a dificuldade dos mediadores (profissionais técnicos e políticos) em interpretar, de maneira adequada, o que os membros das chamadas classes populares estão dizendo. ${ }^{6-8}$ Isso está relacionado mais com a postura de rejeição do saber dessas camadas sociais menos favorecidas, enquanto dispositivo capaz de sistematizar pensamentos sobre a sociedade e, suas necessidades do que a aspectos técnicos como, por exemplo, linguísticos. O saber popular é elaborado a partir da experiência concreta e das vivências que, na maioria das vezes, são distintas daquelas do profissional. "O profissional oferece seu saber porque julga o da população insuficiente, e, por esta razão, inferior, quando, na realidade, é apenas diferente". 6:14

Atualmente, a participação social pode acontecer de duas formas: a participação institucionalizada e que, na área da saúde, pode ser efetivada nos Conselhos e nas Conferências de Saúde onde há representantes de instituições, dos usuários, de prestadores de serviços e do governo. Outra prática participativa pode acontecer nas atividades de educação em saúde, uma vez que se constituem na convivência cotidiana com o usuário, o que possibilita o compartilhamento do saber, o desenvolvimento de uma consciência crítica e reflexiva e o exercício da cidadania. ${ }^{8}$

Muitos dos programas e ações no campo da saúde são planejados e implementados para a população, quando o mais adequado seria que fossem elaborados com a população, em um movimento de interação entre os usuários e os 
trabalhadores dos diversos serviços, por meio de um processo dialógico e de negociação. Assim, surge a possibilidade de desenvolvimento da co-responsabilização do usuário para com as políticas públicas, com as ações federais, estaduais, municipais e locais de saúde, bem como para com sua saúde individual. ${ }^{9}$

Isso corrobora o que foi pactuado na Primeira Conferência Internacional sobre Promoção da Saúde e que está documentado na Carta de Otawa, no que se refere à importância de uma ação coordenada entre diversos setores da sociedade para o desenvolvimento da promoção da saúde: governo, saúde, economia, organizações não-governamentais, bem como os indivíduos, família e comunidades. A promoção da saúde, por sua vez, representa um processo que visa o aumento da capacidade dos indivíduos e comunidades para atuar na melhoria de sua saúde e qualidade de vida. ${ }^{10}$

A promoção da saúde tem, portanto, estreita relação com a educação em saúde que se estabelece a partir da participação da população, de suas necessidades, de seu estilo de vida, crenças e valores, desejos, opções, vivências, da subjetividade e intersubjetividade, no contexto cultural - sócio - político em que vive. Essa participação exige envolvimento, compromisso e solidariedade, enquanto uma construção cotidiana de decisões em conjunto, estabelecidas com todos que participam do processo educativo, que mantêm o compromisso de trocar experiências, vivências, conhecimentos, que são diferentes porque as histórias de cada um foram construídas diferentemente. ${ }^{11}$

A aceitação dessa diferença talvez seja uma das dificuldades do processo educativo, pois pode se tornar um processo longo e muitas vezes conflituoso. Como as pessoas são diferentes, as necessidades também o são e isso pode gerar conflito. Mas é justamente no conflito, na busca de soluções conjuntas, na própria alteridade, que as pessoas crescem e, muitas vezes, descobrem que suas necessidades individuais são da coletividade e muitas das necessidades coletivas podem tornarse suas. É aprender, no dia a dia, a viver uma "harmonia conflitual", presente em todas as relações humanas e que são fundadas na alteridade. ${ }^{12}$

A educação em saúde participativa não se estabelece, portanto, de forma linear nem imediata. É uma construção cotidiana e coletiva, possivelmente inacabada. Não há receitas nem fórmulas para as mudanças de comportamento. É necessário reconhecer que há um caminho extenso a ser percorrido e que as possíveis mudanças não são aquelas que talvez o profissional de saúde pretenda e que nem sempre são visíveis. Não se desejam grandes transformações de ordem política com todas as reivindicações garantidas, mas é necessário reconhecer, como válidas, as mudanças que as pessoas se propõem, pois sempre existem outras possibilidades de agir nos vários espaços da vida das pessoas. ${ }^{13}$ Por isso, o modelo de educação bancária é criticado, uma vez que considera o educando enquanto depósito de conhecimentos que recebe de outro, considerado como detentor do saber. ${ }^{14}$

Desse modo, para que as ações de educação em saúde sejam bem sucedidas, é preciso considerar o contexto cultural dos sujeitos envolvidos no processo, levando-se em conta suas representações sociais a respeito dos aspectos relacionados à saúde. Essas representações, por sua vez, não são tomadas como um sistema fechado, mas sim como um campo aberto que pode se transformar durante as interações indivíduo-indivíduo e indivíduo sociedade. "Hoje se sabe que há um trabalho educativo a ser feito que extrapola o campo da informação, ao integrar a consideração de valores, costumes, modelos e símbolos sociais que levam a formas específicas de condutas e práticas" ${ }^{13: 202}$ De modo geral, as mudanças necessárias para a condução dos processos de educação em saúde têm levado os profissionais de saúde a buscar outros referenciais além dos biológicos, já que se reconhece que as ações que visam uma melhoria na qualidade de vida dos sujeitos estão entrelaçadas com a cultura, ou seja, "com os estilos de vida, hábitos, rotinas e rituais na vida das pessoas". ${ }^{15: 311}$

Todavia, para se obter o conhecimento sobre a cultura dos sujeitos envolvidos nos processos educativos, é preciso torná-los protagonistas desse processo. Isso possibilitará o desenvolvimento de estratégias educativas condizentes com as práticas culturais de determinada comunidade. Ao considerar "a educação como um processo de troca, um processo de ensino-aprendizagem, no qual educandos procuram se conhecer por meio do diálogo, torna-se relevante que a população participe e que as características dessa população sejam valorizadas no cuidado educativo". ${ }^{16: 111}$

A partir dessas considerações, a educação em saúde foi instituída na Linha do Cuidado à Gestante, Puérpera e ao Recém-Nascido com o intuito de contribuir para a promoção da saúde. Essa atividade ocorre em dois espaços institucionais: O Curso de Gestantes e o encontro para discussão do Planejamento Familiar. O Curso é estruturado em três encontros, um em cada trimestre da gesta- 
ção, nos quais se discutem aspectos relacionados à importância do pré-natal, aos cuidados com a gestante e com o recém-nascido, ao aleitamento materno e aos direitos sociais na maternidade. Para se conseguir essa abordagem tão ampla e complexa, foi necessário articular um trabalho interdisciplinar envolvendo enfermeiro, ginecologista, pediatra, psicólogo, odontólogo e acadêmicos do Curso de Graduação em Fisioterapia de uma universidade conveniada com a Prefeitura Municipal de Belo Horizonte. O encontro para discussão do Planejamento Familiar é realizado por uma enfermeira, em uma tarde, e é estruturado em três momentos. No primeiro, faz-se uma discussão sobre o significado e a importância desse planejamento. No segundo, há uma exposição dialógica sobre os diversos métodos contraceptivos. No terceiro, há um atendimento individual para discussão de dúvidas que os usuários não quiseram verbalizar em público e encaminhamentos conforme cada caso. Tanto no Curso de Gestantes quanto no Planejamento Familiar, os temas são discutidos em rodas de conversa onde há abertura para que as usuárias coloquem outros assuntos de seu interesse, bem como seus questionamentos. Essa metodologia foi proposta com o intuito de favorecer a participação das usuárias e a troca de experiências entre elas.

Este artigo é um recorte de uma dissertação de mestrado que teve como objetivo compreender a percepção das usuárias sobre a Linha do Cuidado à Gestante, Puérpera e ao Recém-nascido.

\section{PERCURSO METODOLÓGICO}

No presente trabalho optou-se por um estudo de caso único, com abordagem qualitativa e fundamentado nos pressupostos da Sociologia Compreensiva de Michel Maffesoli. O estudo de caso foi eleito enquanto estratégia de investigação, uma vez que permite maior aprofundamento do objeto de estudo e, "[...] investiga um fenômeno contemporâneo dentro de seu contexto da vida real, especificamente quando os limites entre o fenômeno e o contexto não estão claramente definidos". 17:32 O método qualitativo, por sua vez, é o que se aplica ao estudo da história, das relações, das representações, das crenças e das percepções, produtos das interpretações que as pessoas fazem a respeito de suas vivências, de seu modo de sentir e pensar. ${ }^{18}$ Nessa perspectiva, tornou-se oportuno desenvolver este estudo por meio de uma abordagem qualitativa fundamentada nos pressupostos da Sociologia Compreensiva que valoriza o vivido que se constitui no cotidiano de uma forma dinâmica uma vez que "[...] as palavras tornam-se fúteis quando se desvinculam da realidade vivenciada e deixam de ter energia própria" ${ }^{19: 14}$

O estudo foi realizado na UBS São Gabriel que possui quatro Equipes de Saúde da Família, pertence à Regional Nordeste do município de Belo Horizonte e está sob coordenação do DISANE. É importante ressaltar que o nome dessa UBS foi explicitado mediante Termos de Autorização assinados por sua gerente e pela gerente do DISANE.

Os sujeitos da pesquisa foram usuárias das Equipes de Saúde da Família números 1, 2 e 4, que vivenciaram o cuidado ofertado na Linha do Cuidado à Gestante, Puérpera e ao Recémnascido. Isso se justifica pelo fato de uma das pesquisadoras fazer parte da Equipe número 3 desse serviço de saúde. De acordo com o primeiro critério de inclusão, foram convidadas aquelas usuárias que receberam a assistência de pré-natal e puerpério nessa UBS e que estavam vivenciando a puericultura com o(a) filho(a) que deveria estar, no mínimo, no terceiro mês de vida. Isso foi de fundamental importância para que elas pudessem expressar a percepção não somente de partes da linha do cuidado, mas, também, do todo. Além disso, após o terceiro mês de vida do filho, a participante já teve contato com todos os profissionais envolvidos no cuidado à gestante, à puérpera e à criança. O segundo critério inclui usuárias cujos filhos tenham até um ano e três meses de idade, pois é o período de maior contato delas com o serviço de saúde e, portanto, o objeto de estudo ainda estará muito presente em seu cotidiano. O terceiro critério de inclusão das usuárias na pesquisa foi a exigência de já terem alcançado a maioridade. Portanto, foram incluídas as usuárias com dezoito anos completos ou mais. De acordo com o Art. 5 da Lei $N^{\circ} 10.406$ de 10 de Janeiro de 2002 do Código Civil Brasileiro, a menoridade cessa aos dezoito anos completos, quando a pessoa fica habilitada à prática de todos os atos da vida civil. ${ }^{20}$

A composição da amostra deu-se a partir das listagens de usuárias que preencheram os critérios de inclusão. Foram selecionadas por sorteio, alternadamente, por equipe, totalizando 12 entrevistadas, sendo quatro de cada equipe envolvida na pesquisa. Esse número foi definido pelo critério de saturação dos dados. ${ }^{21}$

A coleta de dados foi realizada por meio de entrevistas semiestruturadas, no período de abril a julho de 2008, direcionadas pelo seguinte roteiro: descreva como foi seu acompanhamento aqui 
na UBS desde o momento em que foi agendada a primeira consulta de pré-natal até o período após o parto; descreva como foi o acompanhamento que seu(sua) filho (a) recebeu aqui na UBS desde o nascimento. O que você pensa sobre o acompanhamento recebido por você e seu filho? O que você gostaria que fosse diferente nesse acompanhamento ? Por quê? Você gostaria de dizer mais alguma coisa? O roteiro para esse tipo de entrevista tem como finalidade direcionar a interlocução e deve ser construído de modo que permita flexibilidade nas "conversas" e a absorção de novos temas e questões interpostos pelo interlocutor, constitutivos de sua estrutura de relevância. Dessa maneira, "deseja-se que a linguagem do roteiro provoque várias narrativas possíveis da vivência que o entrevistador vai avaliar; as interpretações que o entrevistado emite sobre elas e sua visão sobre as relações sociais envolvidas nessa ação". 18:191

Para o tratamento e a análise dos dados coletados, foi utilizada a técnica de análise de conteúdo temática ${ }^{18,22}$ que, operacionalmente, ocorreu em três etapas: Pré-análise - foi feita a ordenação dos dados após a transcrição na íntegra das entrevistas. Em seguida, procedeu-se à leitura flutuante e exaustiva do material buscando a apreensão de seu conteúdo e o desvelar de "mensagens implícitas, dimensões contraditórias e temas sistematicamente silenciados". ${ }^{33: 48}$ Exploração do material - consistiu em uma operação classificatória para identificar os núcleos de compreensão do texto. Inicialmente, recortou-se o texto em unidades de registro e, posteriormente, procedeu-se à classificação e à agregação dos dados. Emergiram, desse processo, os temas mais relevantes que permitiram estabelecer quatro categorias temáticas e, dentre elas, a que originou o título deste artigo. Tratamento dos resultados obtidos e interpretação - as categorias foram interpretadas e discutidas com base no referencial teórico.

Como se trata de uma pesquisa envolvendo seres humanos, o projeto de pesquisa foi aprovado pelos Comitês de Ética e Pesquisa da Universidade Federal de Minas Gerais, pelo Parecer $N^{\circ}$ 544/07 e da Secretaria Municipal de Saúde de Belo Horizonte, CEP-SMSA/PBH, pelo Parecer $\mathrm{N}^{\circ}$ 094/2007. Os sujeitos que concordaram em participar da pesquisa receberam informações sobre o interesse, a justificativa, o objetivo e as finalidades do estudo e assinaram o Termo de Consentimento Livre e Esclarecido antes da realização da entrevista, seguindo as determinações da Resolução $N^{\circ}$ 196/96 do Conselho Nacional de Saúde que trata dos aspectos éticos da pesquisa envolvendo seres humanos. ${ }^{24} \mathrm{O}$ anonimato foi assegurado e as entrevistadas foram identificadas pela letra e a qual foi acrescentado o número da entrevista conforme a sequência de realização.

\section{RESULTADOS E DISCUSSÃO}

Um dos elementos estruturantes da Linha do Cuidado à Gestante, Puérpera e ao Recém-Nascido diz respeito aos espaços instituídos para a educação em saúde: o Curso de gestante e o encontro para discussão do Planejamento familiar. Eles representam práticas de cuidado e visam, principalmente, a promoção da saúde e a emancipação dos sujeitos: a atendente que vai nas casas me falou do curso de gestantes e eu comecei a fazer. O curso foi muito bom, tirou muitas dúvidas. [...] Ensinou muita coisa pra gente. Principalmente do parto porque o maior medo é do parto (e2).

[...] quando falou assim, planejamento familiar, eu imaginei que seria uma ou tra coisa. Eu não imaginei que seria explicado tudo pra gente. Todos os métodos, DIU, tudo (e7).

Esses espaços emergem enquanto dispositivos que permitem tirar dúvidas, além de propiciar o contato com novos conhecimentos. A possibilidade de tirar dúvidas, falar sobre os medos e dificuldades demonstra a importância da abertura ao diálogo nas ações educativas. O fundamental é que o educador e os educandos saibam que sua postura, no processo de comunicação, é dialógica, aberta, curiosa, indagadora e não apassivadora e opressora da curiosidade, já que "é ela que me faz perguntar, conhecer, atuar mais, perguntar, re-conhecer" ${ }^{14: 86}$

A educação em saúde pode promover um aprendizado prático que contribui para tornar as pessoas mais preparadas para lidar com certos acontecimentos e situações que fazem parte da vida e que se relacionam com sua saúde como ilustrado nos relatos a seguir: [...] eu tinha um pouquinho de contração durante a gravidez e aí lá eles falaram que isso é normal, antes de acontecer. Foi melhor ainda porque eu não precisei, eu não passei aperto quando aconteceu, porque eu já sabia que podia acontecer (e8). O curso de gestante me ajudou a amamentar, me ajudou a cuidar dele quando ele nascesse, porque me ensinaram quando ele tivesse cólica, como agir (e3).

Esses depoimentos revelam que houve um aprendizado de coisas simples do cotidiano, mas que foram fundamentais para que as entrevistadas pudessem cuidar melhor de si e dos filhos. Isso evidencia a importância da educação em saúde 
enquanto produtora de um saber que contribui para a autonomia e a emancipação dos sujeitos.

[...] eu resolvi assumir porque não vou ter um risco com o DIU e vou ter outro risco com o anticoncepcional oral ou com a injeção. Aí eu resolvi escolher pelo DIU. Eu acho que essa orientação foi muito boa, muito importante (e8).

O planejamento familiar foi bom também porque a gente tem oportunidade de escolher o método pra prevenir (e11).

Essa ação educativa leva o indivíduo à construção de um conhecimento, possibilitando que os usuários façam escolhas conscientes a respeito dos métodos contraceptivos. Esse aspecto da educação em saúde traz à tona seu potencial de subsidiar a tomada de decisões e a condução de determinadas questões da vida por parte dos sujeitos. Nesse sentido, a educação em saúde se constitui em um processo político e pedagógico que leva ao desenvolvimento de um pensar crítico e reflexivo bem como "[...] a sua autonomia e emancipação enquanto sujeito histórico e social capaz de propor e opinar nas decisões de saúde para o cuidar de si, de sua família e da coletividade" .25:341

A percepção das usuárias revela também a importância do incentivo e da criação de possibilidades para que os sujeitos tenham participação ativa no processo: eu acho que se tiver uma pesquisa de quais são as perguntas mais frequentes, uma resposta a essas perguntas e, talvez, tentar chamar mais todo mundo pra participar, pra não ficar parecendo que, quem participa, já que todo mundo fica quieto, quem participa tá errado (e8). Há um desejo de que a participação seja concebida como uma atitude "certa" e bem vinda para não parecer que quem participa está errado. Para que as atividades em grupo tenham êxito, é preciso conhecer e ouvir cada participante pois, a partir de suas necessidades e vivências, é possível avaliar as dificuldades e encontrar a potencialidade do grupo. ${ }^{26}$

Assim, "nas condições de verdadeira aprendizagem, os educandos vão se transformando em reais sujeitos da construção e da reconstrução do saber ensinado, ao lado do educador igualmente sujeito no processo". ${ }^{14: 26}$ Da mesma forma que "desenvolver a escuta qualificada significa desenvolver a capacidade de ouvir as narrativas e lembrar que a narração de um fato pode modificar a maneira de encará-lo e agir sobre a situação". 14:311 Portanto, saber ouvir representa habilidade fundamental nos processos de educação em saúde.

Além disso, esse relato traz uma reflexão acerca de uma democratização no que se refere aos temas discutidos com o intuito de adequá-los às necessidades das usuárias. Para isso, "é necessário muitas vezes conter o afã profissional de tudo resolver, "dar" condições para que as pessoas vivam melhor pois, muitas vezes, essa forma não condiz com os desejos das pessoas". ${ }^{10: 86}$ Nesse sentido, o trabalho educativo pode transformar a relação existente entre profissional de saúde e usuário tornando-a mais horizontalizada, o que facilita a expressão individual e coletiva das necessidades e expectativas.

Além da possibilidade de construção conjunta do conhecimento, essas ações educativas ganham outras conotações como demonstrado nos discursos.

Então ébacana vocêpegar uma que não teve filho, que é o primeiro bebê e pegar aquela que já teve dois filhos e dividir experiências (e6).

Eu só achei que faltou um pouco de uma apresentação geral. [...] Acho que a mãe fica querendo contar porque que engravidou, acho que algumas até não, mas a maioria quer contar como que é a situação naquele momento, o que que tá vivendo. [...] É um momento de muita sensibilidade e a gente gosta de compartilhar, de muita insegurança (e10).

Esses espaços de educação em saúde também são entendidos enquanto local de interação e trocas de experiências. No entanto, de acordo com o olhar das usuárias, essas ações educativas precisam ser potencializadas como tal, para que se compartilhem não somente vivências e histórias de vida, mas também os sentimentos com quem os vivencia num mesmo espaço de tempo e lugar. Tais aspectos também se evidenciam: Eu participei do planejamento familiar. [...] fiz, também o curso de gestante. Foi diferente, foi legal porque a gente fica muito dentro de casa. Eu sou muito de ficar dentro de casa. Então ébom a gente sentar, conversar, trocar idéias com outras pessoas. Fiz esse curso, gostei também. Teve as brincadeiras, um sorteio, uns negócio assim, divertido. Dá pra aprender, porque tem coisa que a gente sabe e quando vai ver, não sabe de nada (e11).

Há uma necessidade de se sentirem pertencentes a um grupo de pessoas que vivenciam um mesmo fenômeno: a gravidez. "Esse sentimento de pertencimento que lhes confere uma identificação, que não espelha no dever-ser e sim no estar-junto" ${ }^{\prime 1: 87}$ dividindo todas essas experiências. Esse último discurso ressalta que esse espaço de interação traz a possibilidade de construção e/ou re-construção de conhecimentos e, nesse lugar, onde é possível sentar, conversar, trocar idéias o lúdico emerge enquanto dispositivo capaz de tor- 
nar esse momento mais prazeroso, mais divertido, o que demonstra que ele tem um significado no imaginário das pessoas.

Podemos entender que vivemos um tempo na história da humanidade em que as pessoas, mesmo fazendo parte de uma grande massa na sociedade, buscam espaços de comunhão de experiências de vida em grupos onde pode haver um processo de identificação. Os sentimentos, as emoções e as sensações que não são comungados perdem muito de sua intensidade. ${ }^{12}$

Inúmeras constatações empíricas apontam para a saturação do individualismo. A lógica da identidade, que dá suporte a ele é algo inteiramente relativo, já que o homem sofre diversas transformações ao longo da existência. "O indivíduo só pode ser definido na multiplicidade de interferências que estabelece com o mundo circundante". ${ }^{27: 305}$ Nesse sentido, é preciso se reconhecer a labilidade da identidade uma vez que a lógica dessa está nas relações e assume, hoje, uma forma denominada lógica da identificação que determina o estar-junto da socialidade que se expressa nesse compartilhamento de sentimentos, anseios e vivências. Mesmo sabendo que se trata de constatações empíricas, "são situações, manifestações, casos de experiências que são vividos sem que se preste atenção a eles". Determinam um ambiente específico que os intelectuais não têm por hábito considerar como "objeto" de estudo. No entanto, "todos esses elementos delimitam bem a saturação de uma identidade estável e garantida por si mesma". 27:302

Por isso mesmo, o processo educativo não ocorre somente em espaços formalmente instituídos, uma vez que pode emergir em quaisquer encontros entre as pessoas e, consequentemente, naqueles que ocorrem entre profissionais de saúde e usuários, como exemplificado em alguns fragmentos de entrevistas.

Gostei muito da atenção da pediatra e de todos que sempre acompanharam, o pessoal da vacina, me explicou, também, no primeiro dia, a mulher, não sei o nome dela, dúvidas da mama [...] (e9).

[...]. Então isso ajuda muito pra mãe, que às vezes tá naquele momento assim tenso de não saber deitar pra amamentar, como trocar, como segurar. E isso aqui no posto hoje em dia a gente tem visto que eles estão mais assim, eles querem ajudar mais (e6).

Assim, os consultórios, a sala de vacina, a sala de procedimentos de enfermagem representam alguns desses locais onde a educação em saúde pode acontecer quando se tem o propósito e a preparação para por em prática ações educativas. Isso é reconhecido pelas usuárias que vivenciam essa experiência: [...] o que eu não sei fazer, tão me ensinando pouco a pouco. Então foi super tranquilo. [...] É o acompanhamento que vai me dizer se eu tô agindo certo com ele tanto na amamentação, na vacinação, no peso. Então, é importante por causa disso (e3).

O domicílio também aparece como lugar propício para se estabelecerem relações educadoras. Ela me ajudou, me explicou, eu tava toda, assim, cansada, insegura, não tava conseguindo amamentar, tava tensa. Ela falou assim: primeiro você vai relaxare ela entendeu direitinho. Ela viu, ela viu a situação, viu como é que eu tava e soube me orientar. Eu fiquei muito mais tranquila e não precisei nem ir lá no posto. Então eu achei muito bom o agente de saúde. Não tinha isso e é importante essa visita (e10).

Retrata-se, aqui, um cuidado totalmente entrelaçado com a educação em saúde, pois a entrevistada fala de interações que propiciam o aprendizado, mas também a valorização do ser humano, de seus sentimentos e de seu modo particular de vivenciar a experiência da amamentação, o que se constitui, em nosso entendimento, como o segredo da ação transformadora esperada pelo cuidado.

Assim, é possível compreender que a educação em saúde está intimamente relacionada com as ações cuidadoras. Isso nos remete à dupla identidade dos profissionais de saúde - a de educador e a de trabalhador de saúde. Essa duplicidade mostra que a educação ocupa lugar central no trabalho em saúde e, muitas vezes, é o que o torna viável. "Não é possível pensar a saúde sem, simultaneamente, pensar a educação e as relações existentes entre ambas". ${ }^{28: 11}$

\section{CONSIDERAÇÕES FINAIS}

A educação em saúde representa um dos principais elementos para a promoção da saúde e uma forma de cuidar que leva ao desenvolvimento de uma consciência crítica e reflexiva e para a emancipação dos sujeitos ao possibilitar a produção de um saber que contribui para que as pessoas possam cuidar melhor de si e de seus familiares, como demonstrado pelas mulheres que participaram deste estudo. Isso nos mostra que a educação em saúde está intimamente relacionada com o cuidado e nos remete ao duplo papel exercido pelos profissionais de saúde que são também educadores por excelência.

Desse modo, os espaços destinados à educa- 
ção em saúde, na Linha do Cuidado à Gestante, Puérpera e ao Recém-nascido, foram eleitos enquanto dispositivos que propiciam o contato com novos conhecimentos e o aumento da capacidade de fazer escolhas conscientes com relação à condução da própria saúde. Essas ações de educação em saúde também são concebidas enquanto espaço de trocas de experiências, saberes e vivências que também levam à construção e à reconstrução do conhecimento a partir de um processo de identificação entre os atores envolvidos.

Além disso, os relatos das usuárias que vivenciaram processos de educação em saúde no período da gestação, do puerpério e do cuidado ofertado a seus filhos, mostram que a educação em saúde não ocorre somente em espaços formalmente instituídos, uma vez que pode acontecer em quaisquer encontros entre aqueles que cuidam e aqueles que são cuidados.

Pode-se afirmar que houve, nesse processo, uma construção de conhecimento compartilhado, que leva as mulheres a fazerem escolhas conscientes sobre suas condutas em relação à contracepção, a seu corpo. É essa autonomia em relação a si que a educação em saúde propõe.

Ao suscitar a necessidade de estimular a participação das pessoas nos encontros educativos e, a pertinência da democratização no que se refere à escolha dos temas discutidos, os resultados deste estudo levam ao reconhecimento de que a perspectiva normativa e autoritária, que visa a transmissão de informações, não é suficiente para promover o aprendizado.

Após essas reflexões, compreendemos que o trabalho educativo não é uma tarefa simples, sobretudo na saúde, uma vez que não se limita à transmissão de informações aos usuários em relação ao cuidado de si e de sua família. Ao contrário, é uma prática compartilhada, de troca de saberes, a ser desenvolvida no cotidiano do trabalho em saúde. Para tanto, torna-se necessário promover uma prática educativa que visa a participação ativa dos usuários dos serviços de saúde, direcionando esse trabalho de acordo com suas necessidades, crenças, representações e histórias de vida, tornando-os co-produtores desse processo educativo, juntamente com os profissionais de saúde.

\section{REFERÊNCIAS}

1. Alves VS. Um modelo de educação em saúde para o Programa Saúde da Família: pela integralidade da atenção e reorientação do modelo assistencial.
Interface - Comunic, Saúde Educ. 2004 Set - 2005 Fev; 9(16):39-52.

2. Ministério da Saúde (BR), Secretaria de Atenção à Saúde, Coordenação de Saúde da Comunidade. Saúde da Família: uma estratégia para reorientação do modelo assistencial. Brasília (DF): MS; 1997.

3. Secretaria Municipal de Saúde de Belo Horizonte. BH-Vida: promoção da saúde e organização dos serviços. Belo Horizonte (MG): SMSA; 2002.

4. Secretaria Municipal de Saúde de Belo Horizonte. BH-Vida: saúde integral. Belo Horizonte (MG): SMSA; 2003

5. Franco TB, Magalhães Júnior HM. Integralidade na assistência à saúde - a organização das linhas do cuidado. In: Merhy EE, Magalhães Junior HM, Rimoli J, Franco TB, Bueno WS. O trabalho em Saúde: olhando e experienciando o SUS no cotidiano. $4^{\mathrm{a}} \mathrm{ed}$. São Paulo (SP): Hucitec, 2007. p.125-33.

6. Valla VV. Sobre participação popular: uma questão de perspectiva. Ciênc Saúde Coletiva. 2006; 14(Supl 2):7-18.

7. Vázquez ML, Silva MRF, Campos ES, Arruda IKG, Diniz, AS, Veras IL, et al. Participação social nos serviços de saúde: concepções dos usuários e líderes comunitários em dois municípios do nordeste do Brasil. Cad Saúde Pública. 2003 MarAbr; 19(2):579-91.

8. Campos L, Wendhausen A. Participação em saúde: concepções e práticas de trabalhadores de uma equipe da Estratégia de Saúde da Família. Texto Contexto Enferm. 2007 Abr-Jun; 16(2):271-9.

9. Crevelim MA, Peduzzi M. A participação da comunidade na equipe de saúde da família. Como estabelecer um projeto comum entre trabalhadores e usuários?. Ciênc Saúde Coletiva. 2005 Abr-Jun; 10(2):323-31.

10. Organização Mundial de Saúde [página na Internet]. Carta de Ottawa, aprovada na I Conferência Internacional sobre Promoção da Saúde em 1996. [acesso 2009 Out 11]. Disponível em: http:/ / www. opas.org.br/promocao/uploadArg/Ottawa.pdf

11. Penna CMM. Realidade e imaginário no processo de viver de moradores em um distrito brasileiro. Texto Contexto Enferm. 2007 Jan-Mar; 16(1):80-8.

12. Maffesoli M. O conhecimento comum. Compêndio de Sociologia Compreensiva. Tradução de Aluízio Ramos Trinta. São Paulo (SP): Brasiliense; 1988.

13. Gazzinelli MF, Gazzinelli A, Reis, DC, Penna, CMM. Educação em saúde: conhecimentos, representações sociais e experiências da doença. Cad Saúde Pública. 2005 Jan-Fev; 21(1):200-6.

14. Freire, P. Pedagogia da autonomia: saberes necessários à prática educativa. São Paulo (SP): Paz e Terra; 1996.

15. Boehs AE, Monticelli M, Wosny, AM, Heidemann IBS, Grisotti M. A interface necessária entre 
enfermagem, educação e saúde e o conceito de cultura. Texto Contexto Enferm. 2007 Abr-Jun; 16(2):307-14.

16. Souza LB, Aquino OS, Fernandes JFP, Vieira NFC, Barroso MGT. Educação, Cultura e Participação Popular: abordagem no contexto da educação em saúde. Rev Enferm UERJ. 2008 Jan-Mar; 16(1):107-12.

17. Yin RK. Estudo de Caso: planejamento e métodos. $2^{\mathrm{a}}$ ed. Porto Alegre (RS): Bookman; 2005.

18. Minayo MCS. O desafio do conhecimento: pesquisa qualitativa em saúde. $9^{a}$ ed. São Paulo (SP): HUCITEC; 2006.

19. Maffesoli M. O rítimo da vida: variações sobre o imaginário pós-moderno. Tradução de Clóvis Marques. Rio de Janeiro (RJ): Record; 2007.

20. Brasil. Lei $\mathrm{N}^{\circ} 10.406$, de 10 de janeiro de 2002 [página na Internet]: Institui o Código Civil. Diário oficial da União, 11 de janeiro de 2002. [acesso 2007 Jul 23]. Disponível www.planalto.gov.br/CCIVIL/ leis/2002/L10406.htm.

21. Fontanella BJB, Ricas J, Turato ER. Amostragem por saturação em pesquisas qualitativas em saúde: contribuições teóricas. Cad Saúde Pública. 2008 Jan; 24(1):17-27.
22. Bardin L. Análise de conteúdo. Tradução de Luis Antero Reto e Augusto Pinheiro. Lisboa (PT): Edições 70; 1977.

23. Lüdke M, André MEDA. Pesquisa em educação: abordagens qualitativas. São Paulo (SP): EPU; 1986.

24. Ministério da Saúde (BR), Conselho Nacional de Saúde, Comissão Nacional de Ética em pesquisa. Resolução No196 de 10 de outubro de 1996: diretrizes enormas regulamentadoras de pesquisas envolvendo seres humanos. Brasília (DF): MS; 1996.

25. Machado MFAS, Monteiro EMLM, Queiroz DT, Vieira NFC, Barroso MGT. Integralidade, formação de saúde, educação em saúde e as propostas do SUS - uma revisão conceitual. Ciênc Saúde Coletiva. 2007 Mar-Abr; 12(2):335-42.

26. Teixeira E. Práticas educativas em grupo com uma tecnologia sócio-educativa: vivências na Ilha de Caratateua. Esc. Anna Nery. 2007 Jan-Mar; 11(1):155-9.

27. Maffesoli M. No fundo das aparências. Petrópolis (RJ): Vozes; 1996.

28. Gazzinelli MF, Reis DC, Marques RC. Educação em saúde: teoria, método e imaginação. Belo Horizonte (MG): Editora UFMG; 2006. 